\title{
Eficiência do processo de licenciamento ambiental na exploração minerária em
}

\section{Marabá: Um estudo de caso}

\author{
Efficiency of the environmental licensing process in mining exploration in Marabá: A case study \\ Eficiencia del proceso de licencias ambientales en exploración minera en Marabá: Estudio de caso
}

Recebido: 26/04/2021 | Revisado: 04/05/2021 | Aceito: 12/05/2021 | Publicado: 29/05/2021

\author{
Brenda Larissa Silva Maia \\ ORCID: https://orcid.org/0000-0001-6050-9560 \\ Universidade do Estado do Pará, Brasil \\ E-mail:eng.brendamaia@gmail.com \\ Caroline Moura Vilhena \\ ORCID: https://orcid.org/0000-0003-4562-2957 \\ Universidade do Estado do Pará, Brasil \\ E-mail:vilhena-caroline@ hotmail.com \\ Glauber Epifânio Loureiro \\ ORCID: https://orcid.org/0000-0002-0801-5296 \\ Universidade do Estado do Pará, Brasil \\ E-mail:epfanio@uepa.br.
}

\begin{abstract}
Resumo
O crescimento da indústria minerária no estado do Pará tem apresentado não somente benefícios econômicos, mas principalmente passivos ambientais decorrentes da exploração do minério de manganês na região. Nesse sentido, um dos instrumentos mais importantes usado pelo Estado para gerir e exercer o controle das atividades que interferem no meio ambiente é o licenciamento ambiental. Os procedimentos para a obtenção das licenças ambientais têm se tornado cada vez mais difíceis devido as exigências dos órgãos responsáveis, o que tem gerado ampla discussão no ambiente político quanto a real eficiência do processo de licenciamento. Nesse aspecto, este artigo apresenta-se como um estudo de caráter exploratório, baseado na análise documental de quatro empreendimentos com o objetivo de examinar a eficiência do processo ambiental no âmbito da Administração Pública no município de Marabá. O método utilizado na pesquisa focou-se na aplicação de listas de verificação. As falhas observadas dentro da máquina pública bem como estudos ambientais deficientes influenciam na dinâmica do processo, culminando em um procedimento administrativo majoritariamente burocrático.
\end{abstract}

Palavras-chave: Processo ambiental; Burocracia; Serviço público.

\begin{abstract}
The growth of the mining industry in the state of Pará has shown not only economic benefits, but mainly environmental losses due to the exploitation of manganese ore in the region. In this sense, one of the most important instruments used by the State to manage and exercise control over activities that interfere with the environment is environmental licensing. Procedures for obtaining environmental licenses have become increasingly required in accordance with the requirements of the responsible bodies, which is generated by the wide discussion in the political environment regarding a real licensing process. In this aspect, this article presents itself as an exploratory study, based on the documentary analysis of four enterprises with the objective of efficiency of the environmental process within the scope of Public Administration in the municipality of Marabá. The method used in the research focused on the application of checklists. The flaws observed within the public machinery as well as deficient environmental studies influence the dynamics of the process, culminating in a mostly bureaucratic environmental licensing process.
\end{abstract}

Keywords: Environmental process; Bureaucracy; Public service.

\section{Resumen}

El crecimiento de la industria minera en el estado de Pará ha mostrado no solo beneficios económicos, sino principalmente pasivos ambientales derivados de la explotación de mineral de manganeso en la región. En este sentido, uno de los instrumentos más importantes que utiliza el Estado para gestionar y ejercer control sobre las actividades que interfieren con el medio ambiente es el licenciamiento ambiental. Los trámites para la obtención de licencias ambientales se han vuelto cada vez más difíciles debido a los requerimientos de los órganos responsables, lo que ha generado una amplia discusión en el entorno político sobre la eficiencia real del proceso de licenciamiento. Al respecto, este artículo se presenta como un estudio exploratorio, basado en el análisis documental de cuatro proyectos con el objetivo de examinar la eficiencia del proceso ambiental en el ámbito de la Administración Pública en el municipio de Marabá. El 
método utilizado en la investigación se centró en la aplicación de listas de verificación. Las fallas observadas dentro de la maquinaria pública, así como los estudios ambientales deficientes, influyen en la dinámica del proceso, culminando en un procedimiento administrativo mayoritariamente burocrático.

Palabras clave: Proceso ambiental; Burocracia; Servicio publico.

\section{Introdução}

O minério de manganês tornou-se importante mundialmente devido ao crescimento da indústria de aço que o utiliza como matéria prima no processo de fabricação de ligas metálicas (Dias; Caxito, 2018). O Brasil está entre os países com as maiores reservas do mundo, e em 2018 sua produção bruta de minério de manganês chegou à marca de 5.805 .557 toneladas (ANM, 2018).

Dentro da Província Mineral de Carajás encontra-se o município de Marabá, junto ao município de Parauapebas, localizados na região sudeste do Estado do Pará (Afonso, 2019). Esta possui grande importância econômica-ambiental, tanto local quanto nacionalmente por sua atividade mineral, que no ano de 2018 foi responsável por $68 \%$ de todo concentrado de manganês gerado no país (ANM, 2018).

As atividades de extração e beneficiamento de minério de manganês estão sujeitas ao procedimento de licenciamento ambiental (CONAMA, 1997), direcionado a empreendimentos passiveis de impacto ambiental, tais como poluição do ar e das águas, degradação do solo, vibrações, comprometimento paisagístico e ruídos (Chaves, 2013). Alguns desses são considerados impactos sequentes, ocorrendo em cadeia a partir do primeiro evento (Oliveira et al., 2016).

Desse modo, o procedimento de licenciamento ambiental tem sido foco constante de questionamentos referentes a sua real eficiência. Fonseca e Resende (2016) apontam dentro da atual crise no sistema brasileiro de licenciamento ambiental, alguns aspectos mais frequentes como as demoras injustificadas, exigências burocráticas, decisões pouco fundamentadas e contaminação ideológica do processo (Farias, 2019; Gay, 2019).

Em contraste, Oliveira e Andery (2017) apontam como fatores determinantes à crise burocrática a existência de falhas na formalização dos processos por parte dos empreendedores, fazendo com que o órgão ambiental faça a solicitação de informações complementares para subsidiar a continuidade da análise dos processos.

Neste sentido, valendo-se da situação econômica e política pela qual o país atravessa no ano de 2020 a matéria proposta pelo Projeto de Lei n $3.729 / 2004$ busca através da regulamentação do licenciamento ambiental facilitar a retomada do crescimento econômico (Miranda et al., 2016), todavia, a tramitação do PL se espaça ao longo dos anos por acarretar, direta ou indiretamente, em maior ou menor proporção consequências ao patrimônio ambiental de toda a sociedade brasileira (Medeiros, 2018).

Como instrumento, o procedimento de licenciamento é imprescindível para a gestão ambiental, no qual é composto por diretrizes, atividades administrativas e operacionais, tais como planejamento, direção, controle, alocação de recursos e outras, realizadas com o objetivo de obter efeitos positivos sobre o meio ambiente (Milaré, 2015). Logo, diante da crescente pressão pública e da formação de passivos, faz-se necessário a contínua apreciação dos mecanismos consolidados instrumentos de política pública e de gestão ambiental (Oliveira et al., 2016), para tanto o presente trabalho objetivou analisar a eficiência do processo de licenciamento ambiental como instrumento de controle ambiental para atividades de exploração de minério de manganês em Marabá-PA a partir da conformidade legal dos empreendimentos e do rito processual corrente no órgão no que tange o licenciamento ambiental para exploração de minério de Manganês.

\section{Metodologia}

Com o intuito de conhecer o panorama do licenciamento ambiental em Marabá e sua eficiência processual, este estudo é classificado como pesquisa de caráter qualitativo, de natureza básica, sendo seus objetivos classificados, segundo Gil (2002), 
de cunho exploratório, em que seu propósito tem por finalidade causar maior familiaridade com o problema, com vistas a tornálo mais explícito ou a constituir hipóteses.

O delineamento desta pesquisa foi realizado a partir da análise documental dos processos de Licença de Instalação, Operação e Renovação para 04 (quatro) empreendimentos localizados no município de Marabá, sendo todos do setor mineral de manganês.

Para o desenvolvimento do estudo de caso foram selecionados 04 (quatro) empreendimentos, identificados como P1, P2, P3 e P4 com processos de licenciamento ambiental da atividade de pesquisa mineral com lavra experimental, subordinados a SEMAS Unidade Regional (URE) - Marabá.

Das 04 (quatro) solicitações, 02 (duas) são referentes a Licença de Instalação e Operação (LIO) e as outras 02 (duas) pertinentes a Renovação de Licença de Operação. Posto isto, todos os processos foram adquiridos por meio da plataforma SEMAS - SIMLAM Público, conforme demonstrado nas Figuras 1 e 2 abaixo.

Figura 1 - Acesso ao sistema SIMLAM Público.

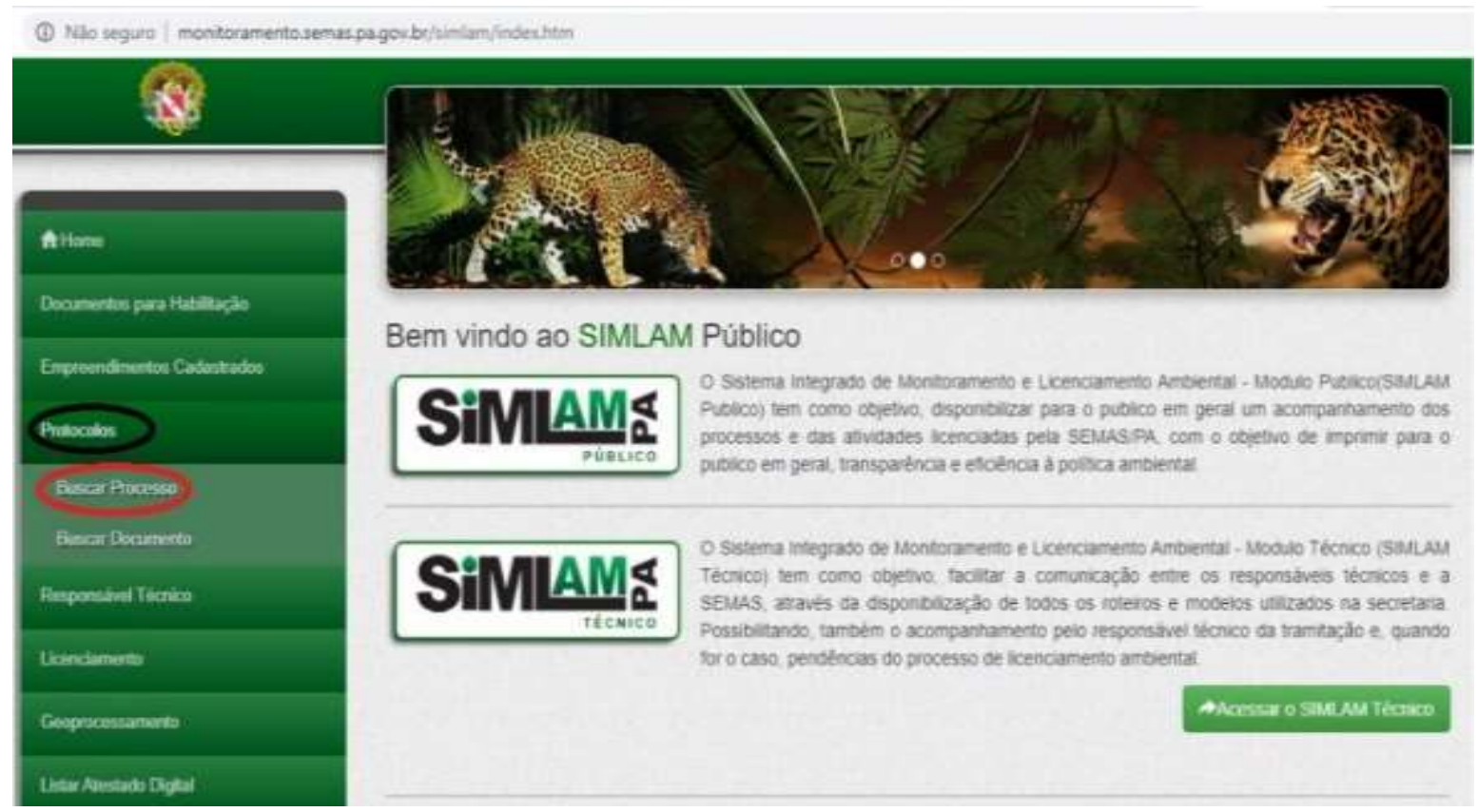

Fonte: Autores (2020). 
Figura 2 - Busca dos processos.

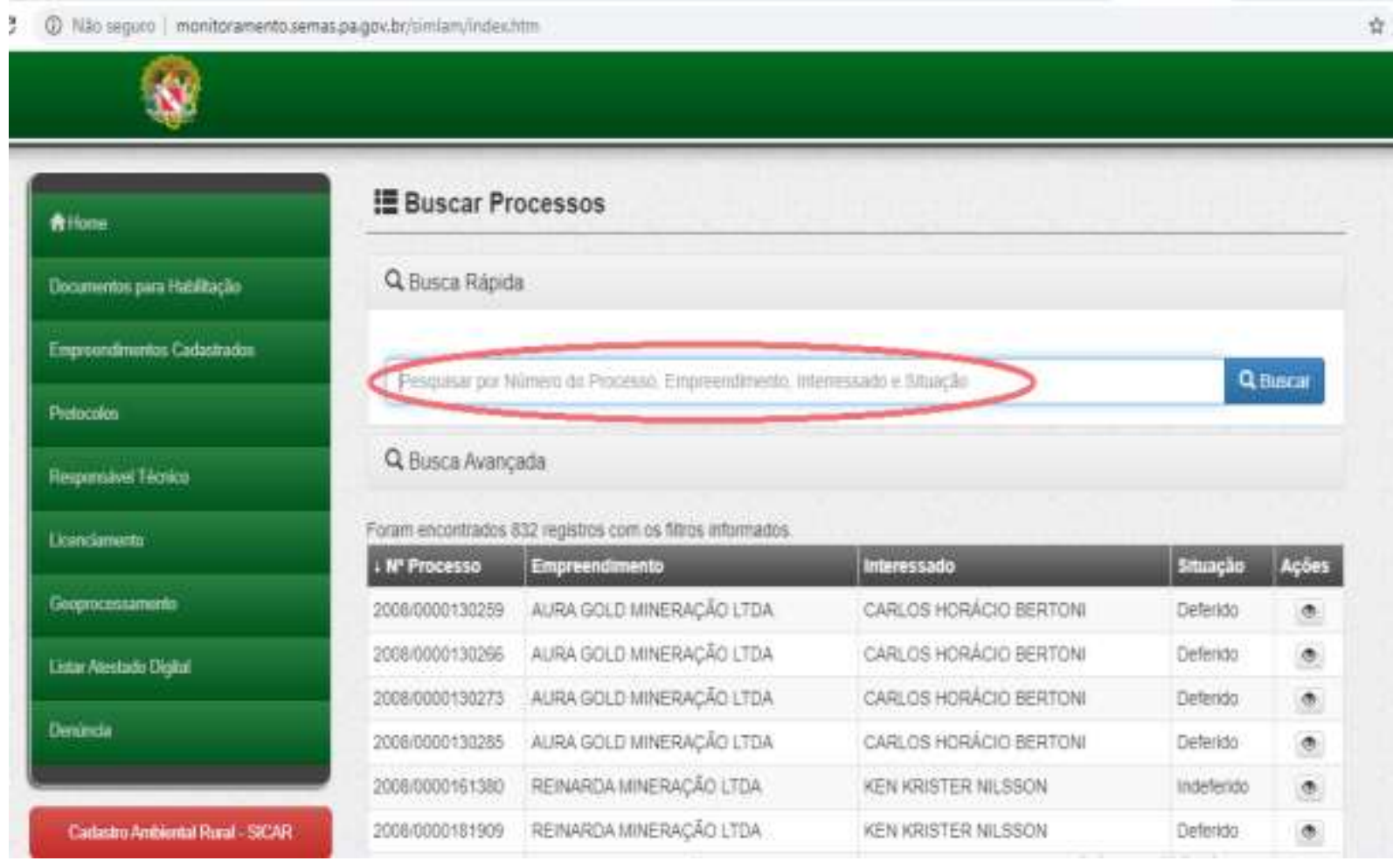

Fonte: Autores (2020).

A pesquisa foi realizada por meio da elaboração e aplicação de listas de verificação adaptadas à metodologia de Silva Junior (2016). Dessa maneira, as listas de verificação utilizadas dividem-se em 09 (nove) variáveis, sendo 04 (quatro) variáveis de base legal e 05 (cinco) de base técnica.

O peso adotado para cada variável foi baseado nos pesos utilizados na literatura, para cada lista de verificação a soma dos pesos atribuídos as variáveis totalizam 100 (cem), nesses termos, todas as variáveis são analisadas em critério de presença/ausência.

Para a elaboração da lista de verificação de base legal, tomou-se como suporte o preenchimento correto do Termo de Referência (Pará, 2019) e (CONAMA, 1990; 1986), além do protocolo dos documentos necessários a solicitação, para o pedido de Licença de Instalação (LI) deverá ser apresentado o Plano de Controle Ambiental (PCA) e autorização para o desmate da área expedido pelo órgão competente. Para o requerimento de pedido de Licença de Operação deverão também ser apresentados a cópia da concessão da LI e a cópia autenticada da Portaria de Lavra.

$\mathrm{Na}$ análise dos estudos ambientais apresentados considerou-se a metodologia de CONAMA (1986), que determina a apresentação do diagnóstico dos meios físicos, biótico e socioeconômico, a avaliação dos impactos através da identificação, previsão da magnitude e interpretação dos impactos relevantes sendo classificados como positivos e negativos, diretos e indiretos, imediatos, a médio ou a longo prazo, reversibilidade, propriedades cumulativas e sinérgicas e apresentação de medidas mitigadoras.

A lista de verificação proposta para Atributos Legais (Tabela 1) são descritas de $\mathrm{VL}_{1}$ a $\mathrm{VL}_{4}$, sendo que as $\mathrm{VL}_{1}$ e $\mathrm{VL}_{2}$ tratam dos documentos administrativos e informações comuns a todas as fases do processo de licenciamento. A variável descrita em $\mathrm{VL}_{3}$ refere-se ao tipo de estudo ambiental apresentado pelo empreendimento. Posteriormente, a VL 4 apresenta-se subdivida em três (03) itens que avaliam as informações sobre o empreendimento, o diagnóstico da área de influência do projeto e os impactos ambientais. 
O peso para a $\mathrm{VL}_{1}$ e VL 3 baseia-se no critério de eliminação dos demais itens, sendo escolhido somente uma opção, e para as variáveis seguintes os pesos dos itens são somados entre si.

Tabela 1 - Lista de verificação de atributos legais.

\begin{tabular}{|c|c|c|c|}
\hline VL & $\begin{array}{l}\text { Peso } \\
\text { Total }\end{array}$ & Itens/Variáveis & Peso \\
\hline ITEM 01 & & Renovação Licenciamento (LP+LI ou LO) & 10 \\
\hline Item 02 & & Licenciamento corretivo (LIC ou LOC) & 06 \\
\hline Item 03 & & Dispensa de licenciamento ambiental (DLA) & 03 \\
\hline VL2 & 15 & Documentos necessário para emissão da LO (LOC ou LOP) & \\
\hline Item 01 & & Requerimento de Renovação da LO & 03 \\
\hline Item 02 & & Cópia publicação do pedido de renovação da LO & 03 \\
\hline Item 03 & & Cópia da publicação da concessão da LO & 03 \\
\hline Item 04 & & Documento ANM (Título autorizativo / Guia de utilização) & 06 \\
\hline VL3 & 20 & Trata do tipo de estudo ambiental apresentado & \\
\hline Item 01 & & PCA & 20 \\
\hline Item 02 & & $\mathrm{RCA}$ & 19 \\
\hline VL4 & 55 & Trata dos componentes do PCA/RCA & \\
\hline \multirow[t]{3}{*}{ Item 01} & 10 & Trata das informações sobre o empreendimento & \\
\hline & & Traz informações sobre o histórico do empreendimento & 07 \\
\hline & & Porte e potencial poluidor degradador & 03 \\
\hline \multirow[t]{4}{*}{ Item 02} & 15 & Trata do diagnóstico ambiental da área de influência do projeto & \\
\hline & & Descrição do meio físico & 05 \\
\hline & & Descrição do meio biótico & 05 \\
\hline & & Descrição do meio antrópico & 05 \\
\hline \multirow[t]{7}{*}{ Item 03} & 30 & Trata das análises dos impactos ambientais & \\
\hline & & Identificação dos impactos positivos/negativos & 05 \\
\hline & & Identificação dos impactos diretos/indiretos & 05 \\
\hline & & Identificação dos impactos imediatos/médio prazo/longo prazo & 05 \\
\hline & & Determinação do grau de reversibilidade dos impactos & 05 \\
\hline & & Previsão da magnitude dos impactos & 05 \\
\hline & & Determinação das propriedades cumulativas e sinérgicas dos impactos & 05 \\
\hline Total & & & 100 \\
\hline
\end{tabular}

Fonte: Autores (2020).

Para a lista de verificação referente aos documentos técnicos conforme a Tabela 2, utilizou-se a metodologia de Pará (2019), sendo as Variáveis Técnicas do Processo (VTP 1 ) o requerimento padrão da SEMAS devidamente preenchido e assinado, Declaração de Informações Ambientais (DIA), documento de identificação do proprietário, cadastro de técnico de atividades de 
defesa ambiental (CTDAM), comprovante de pagamento de taxas, cópia da publicação no Diário Oficial do Estado ou local de grande circulação, dentre outros.

$\mathrm{A} \mathrm{VTP}_{2}$ tem como critério a presença ou ausência dos documentos na plataforma de acesso à informação do órgão. A variável $\mathrm{VTP}_{3}$ considerou a conformidade dos documentos protocolados com o termo de referência disponibilizado pelo órgão por meio da Instrução Normativa No 11/2019 para montagem do processo de licenciamento ambiental.

Para avaliação de atendimento de prazos estabelecidos, a VTP 4 considerou o preconizado por (CONAMA, 1997) e ainda na $\mathrm{VTP}_{5}$ foi observado como se dá licenciamento ambiental considerando a contrapartida do órgão na exigência de documentação complementares ao processo. Desse modo, a $\mathrm{VTP}_{1} \mathrm{VTP}_{2}, \mathrm{VTP}_{3}, \mathrm{VTP}_{4} \mathrm{eVTP}_{5}$ tratam do procedimento técnico do órgão ambiental frente às documentações protocoladas.

Além dos dados encontrados, também foram verificados e analisados a partir da publicação no site do SIMLAM o histórico da tramitação de documento de cada empreendimento.

Tabela 2 - Lista de verificação do procedimento técnico pós homologação.

\begin{tabular}{|c|c|c|c|}
\hline VTP & $\begin{array}{l}\text { Peso } \\
\text { Total }\end{array}$ & Itens/Variáveis & $\begin{array}{c}\text { Peso } \\
\text { Atribuído }\end{array}$ \\
\hline VTP1 & 13 & Avalia o correto preenchimento dos formulários padrão & \\
\hline Item 01 & & Todos os formulários foram cumpridos corretamente & 13 \\
\hline Item 02 & & $\begin{array}{l}\text { Um (ou mais) formulário(s) foi (foram) cumprido(s) corretamente e } \\
\text { outro(s) medianamente }\end{array}$ & 10 \\
\hline Item 03 & & Todos os formulários foram cumpridos medianamente & 7 \\
\hline Item 04 & & $\begin{array}{l}\text { Um (ou mais) formulário(s) foi (foram) cumprido(s) medianamente e } \\
\text { outro(s) não foi (foram) cumprido(s) }\end{array}$ & 4 \\
\hline Item 05 & & Nenhum dos formulários foram cumpridos & 1 \\
\hline VTP2 & 20 & Avalia a presença de todos os documentos no SIMLAM & \\
\hline Item 01 & & Sim, todos os documentos encontram-se no SIMLAM & 20 \\
\hline Item 02 & & Não, nem todos documentos encontram-se no SIMLAM & 5 \\
\hline \multirow[t]{6}{*}{ VTP3 } & 16 & Apresentam-se em ordem de acordo o termo orientativo do órgão & \\
\hline & & Apresenta ordenação completa $(100 \%)$ & 16 \\
\hline & & Apresenta ordenação satisfatória (entre 70 e $99 \%$ ) & 10 \\
\hline & & Apresenta ordenação mediana (entre 40 e $69 \%$ ) & 7 \\
\hline & & Apresenta ordenação insatisfatória (entre 20 e $39 \%$ ) & 4 \\
\hline & & Apresenta ordenação inábil (19\% ou menos) & 0 \\
\hline \multirow[t]{3}{*}{ VTP4 } & 32 & Avalia o tempo de deferimento/indeferimento & \\
\hline & & Até 180 dias & 32 \\
\hline & & Mais de 180 dias & 5 \\
\hline \multirow[t]{4}{*}{ VTP5 } & 19 & Avalia a solicitação de documentação complementar & \\
\hline & & Não apresenta solicitação & 19 \\
\hline & & Apresenta um ou dois documentos solicitados & 10 \\
\hline & & Apresenta mais de dois documentos solicitados & 00 \\
\hline Total & & & 100 \\
\hline
\end{tabular}

Fonte: Autores (2020). 
Para a obtenção dos resultados, foram utilizados os Índices de Concordância (Equação 1) de cada variável que são representados matematicamente pela relação entre o somatório do peso atribuído $\sum_{j} \quad i(V) j$ a cada item ao peso correspondente à variável $\sum_{j} \quad V(L)$ (Silva Junior; Alvarenga; Garcia, 2018).

$$
I C V=\frac{\sum_{j} \quad i(V) j}{\sum_{j} \quad V(L)} \quad \text { (Equação 1) }
$$

$I C V$ = Índice de concordância da variável;

$\sum_{j} \quad i(V) j$ Somatório das notas atribuídas a cada item;

$V(L)=$ Valor máximo que a variável pode assumir;

$j=\mathrm{j}$-ésimo item da variável;

$i=$ item da variável.

Os resultados de concordância obtidos para as listas legais e técnicas foram multiplicados por 100 (cem) afim de classificá-los em grau de conformidade como descrito por Silva Junior, Alvarenga e Garcia (2018):

- De 0,0 a 20,0: muito baixa;

- De 21,0 a 40,0: baixa;

- De 41,0 a 60,0: média;

- De 61,0 a $80,0:$ alta;

- De 81,0 a 100,0 : muito alta.

\section{Resultados e Discussões}

\section{Características Gerais dos Empreendimentos}

Para a empresa P1 foi observado que a solicitação de Licença de Operação (LO) se deu no ano de 2018. A instituição possui sete funcionários, e sua propriedade é de 9.982,8 hectares. Dentro da Guia de Utilização (GU), não há informações relacionadas a produção da empresa, conforme inicialmente havia sido declarado no Requerimento Padrão.

A empresa P2 solicitou a SEMAS pedido de Licença de Instalação e Operação (LIO) além de Autorização de Supressão de Vegetação (ASV) na data de 20 de janeiro de 2018, e não informou a quantidade de seu quadro de funcionários. Segundo o preenchimento do Requerimento Padrão a empresa encontra-se em uma área de 49,48 hectares, no entanto sua área requerida seria de 10,58 hectares. Na GU apresentado foi autorizado a produção de 6000 toneladas/ano de minério de manganês.

Dentre os documentos apresentados na P3 foi verificado a solicitação de Renovação de LO, sendo que o empreendimento opera com 10 (dez) funcionários, em uma área de 320,05 hectares. Com o observado da GU constatou-se a autorização de 50.000 toneladas por ano. Para a P4 observou-se a existência de sete funcionários, e área autorizada de 13,87 hectares, com 6000 toneladas por ano, conforme Portaria 530 do DNPM (Departamento Nacional de Produção Mineral) atual ANM (Agência Nacional De Mineração).

\section{Índice de Concordâncias para Variáveis Legais}

A análise dos estudos ambientais apresentados objetivou comprovar o comportamento legal dos proponentes frente ao órgão ambiental, com destaque para o diagnóstico ambiental da área. Com base em $\mathrm{VL}_{1}$ todos os empreendimentos iniciaram seus processos com a solicitação da licença prévia. Isto demonstra que para esses quatro casos não foi necessário a aplicação de licenciamento corretivo. 
Para Almeida e Montaño (2015), o licenciamento corretivo é resultante de artimanhas do empreendedor, pois quando o empreendimento está instalado torna-se mais difícil a desativação do projeto, uma vez que todos os impactos já estão consolidados. Assim, constatou-se que o objetivo principal do licenciamento, para esses quatro casos, está atrelado ao princípio da prevenção, uma vez que seu propósito é minimizar a ocorrência de impactos negativos.

Para a $\mathrm{VL}_{2}$ que trata dos documentos necessários para a emissão das licenças de operação foi observado que P1(anexo A) e P4 (anexo D) apresentaram 60\% dos documentos necessários para a emissão da mesma. Nos empreendimentos P2 (anexo B) e P3 (anexo C) foram verificados $80 \%$ dos documentos anexados ao processo. E dessa forma, entende-se que alguns documentos são mais relevantes para o processo. Foi constatado, por exemplo, que anexos como a cópia da publicação do pedido de LO são ignorados quando comparados com o documento liberado pela ANM, apesar de ambos serem itens obrigatórios segundo o CONAMA (1990).

Em consonância com os resultados deste artigo, Silva Junior (2016) apresenta conclusões semelhantes para a VL2, no qual também foi evidenciado que os empreendimentos obtiveram suas licenças mesmo não apresentando toda a documentação exigida.

Para a $\mathrm{VL}_{3}$ somente a P2 apresentou nota máxima para esta variável, uma vez que o estudo apresentado foi o PCA, item obrigatório segundo a resolução CONAMA 09/90 para a emissão da LO. A P1 e a P3 apresentam Relatórios Ambientais, e para na P4 não foram encontrados nenhum estudo ambiental referente ao pedido de Renovação de LO.

Desse modo, é possível compreender que a ausência de qualquer estudo ambiental resulta no atraso das atividades e do processo. Pois essas informações servirão de base para a tomada de decisões que visam monitorar os impactos negativos causados pela atividade. Fonseca, Montaño e Moretto (2017) corroboram que a apresentação de estudos ambientais no processo de licenciamento ambiental das instituições contribuem para o monitoramento e consequente mitigação dos impactos.

Dentro deste estudo a $\mathrm{VL}_{4}$ possuiu o maior peso para os processos de licenciamento, pois tratou da análise dos componentes dos estudos apresentados. Ou seja, a VL 4 determinou os pesos adquiridos pelos Índices de Concordância, sendo que esses valores variaram entre a classificação Muito Baixa até Muito Alta.

A empresa P1 alcançou um valor igual a 65 (sessenta e cinco) de concordância legal, obtendo sua classificação Alta, devido ao Relatório de Controle Ambiental (RCA) apresentado ao órgão responsável. Dentro do estudo foi possível verificar as variáveis que tratam dos impactos, como a identificação dos impactos positivos/negativos, diretos/indiretos, como também a previsão de magnitude desses impactos.

A falha observada, e que comprometeu a maior classificação, foi identificada dentro do estudo que contemplou somente o diagnóstico do meio físico da área de influência do projeto. Isso demonstra que não foram avaliados o meio biótico e antrópico, que são tão importantes quanto o meio físico. Ainda que o estudo fosse voltado somente para a avaliação do meio físico, deixouse de serem avaliados outras variáveis também previstas na legislação.

A exemplo, a ausência de avaliação dos itens de identificação dos impactos imediatos, de médio/longo prazo, o grau de reversibilidade, e propriedades cumulativas, previstos como parte constituinte dos estudos ambientais. O estudo de Gallardo et al., (2017) faz uma análise sobre a avaliação de impactos cumulativos e corrobora que os mesmos raramente são considerados em estudos ambientais, embora sejam relevantes para tomada de decisão do órgão responsável.

Após o andamento do processo e das atividades, foram solicitados a P1 a necessidade de apresentação de Estudo de Impacto Ambiental e respectivo Relatório de Impacto Ambiental (EIA-RIMA).

Para a P2, o Índice de Concordância Legal equivaleu a 87 (oitenta e sete) e indicou uma classificação muito alta, isso porque diferentemente da empresa P1, em seu estudo ambiental foram contemplados a avaliação de todos os meios previstos em lei, sendo físico, biótico e antrópico, respectivamente. O Plano de Controle Ambiental tratou da identificação dos impactos positivos/negativos, direto/indireto, considerando o grau de reversibilidade, e a previsão de magnitude. 
No entanto, mesmo com os estudos mais detalhados, o empreendimento não avaliou as propriedades cumulativas e sinérgicas e por isso na avaliação dos Índices de Concordância não obteve o valor máximo de 100 (cem). Vale citar que a Licença de Operação expedida para tal empresa possui validade até o mês de setembro de 2020.

O empreendimento P3 solicitou a Renovação de LO e apresentou um Relatório de Informações Ambientais (RIAA), de modo que obteve o valor do Índice de Concordância Legal de 53 (cinquenta e três), equivalente a classificação Média. O RIAA apresentou os principais impactos negativos, com suas respectivas medidas mitigadoras. Porém, apesar de serem citados alguns planos e/ou programas, não foram encontrados tais documentos, tampouco indicadores de monitoramento em seu estudo.

Outro ponto verificado nesse processo, foi a mudança de titularidade da empresa, o que dificulta o trâmite de análise dos dados antes apresentados. No entanto, foi possível perceber que mesmo com a mudança a instituição não apresentou os indicadores de monitoramento.

O menor Índice de Concordância Legal foi atribuído a instituição P4, classificada como Muito Baixa, sendo atribuído o valor de 19 (dezenove). Essa empresa também solicitou a Renovação da LO, porém não foi anexado nenhum estudo ambiental do tipo relatório no pedido realizado no ano de 2019. No site do SIMLAM foi possível encontrar um estudo ambiental associado ao processo de pedido inicial de licença no ano de 2017. Somado a isto, foi possível perceber mudança na titularidade da instituição, assim como verificado no histórico de tramitação não houve movimentações de documentos associadas ao referido empreendimento.

\section{Índices de Concordância para Variáveis Técnicas}

No que tange os procedimentos administrativos pós homologação do processo junto a secretaria, a lista de verificação para variáveis técnicas, no item $\mathrm{VTP}_{1}$ avaliou o correto preenchimento de formulários padrão e apenas o processo P2 (anexo B) não obteve total conformidade em função da realização do protocolo devido à ausência de informações no documento.

Para variável $\mathrm{VTP}_{2}$, que avalia a presença de toda documentação no SIMLAM apenas o empreendimento P2 obteve peso máximo para avaliação de concordância, evidenciando fragilidade na disponibilidade de acesso a informação garantida em lei. Este fato corrobora com o estudo realizado por Fonseca e Resende (2016), que aponta a Região Norte como a que obteve pior nível de atendimento às boas práticas de transparência e informatização no licenciamento, embora possuam sistemas informatizados de controle de licenciamento ambiental, ainda estão em um estágio incipiente de controle, de modo que seus sistemas permitem um acompanhamento dificultoso nos processos em fase de licenciamento ou pós-licença.

A variável denominada $\mathrm{VTP}_{3}$, avaliou a organização e a conformidade com o termo de referência fornecido pelo órgão, nessa etapa os processos P1(anexo A), P3 (anexo C), cumpriram de 70\% a 99\% e P2 100\% do ordenado pelo órgão, logo, uma ordenação satisfatória. O empreendimento P4 (Anexo D) foi o que obteve menor conformidade no cumprimento do termo de referência tendo sua homologação efetuada mesmo cumprindo apenas o intervalo de $40 \%$ a $69 \%$ da exigência documental do órgão ambiental o que sinaliza um baixo grau de minúcia por parte da administração púbica no aceite de processos de licenciamento.

Desse modo, o estudo de Fatorelli e Mertens (2010) também apontam a falta de comunicação entre setores como as principais causas da fragilidade tecno operacional dentro das instituições ambientais regulamentadoras.

A variável $\mathrm{VTP}_{4}$ tratou sobre o atendimento a legislação sobre prazos máximos para o parecer definitivo por parte do órgão licenciador, nesta etapa nenhum dos empreendimentos analisados obtiveram seu parecer em um período igual ou inferior a 180 dias, como preconiza a legislação, sendo a vagareza do processo um comprovante da disfunção no processo burocrático regido pelo órgão.

Todavia, Oliveira e Andrey (2017) apontam que, embora a atividade de licenciamento ambiental mereça destaque no planejamento, por demandar prazos significativos inerentes ao rito processual, na grande maioria dos empreendimentos que 
implicaram um acréscimo de prazo de até $60 \%$ ao estabelecido na legislação são processos em que houve necessidade de documentação complementar, como observado em P1, P2, P3 e P4.

A última variável analisada para avaliação de conformidade $\mathrm{VTP}_{5}$ deteve-se a necessidade de solicitação de documentação complementar, os empreendimento P1 e P4 foram notificados solicitando um ou dois itens de pendência, o empreendimento P2 teve mais de 2 (dois) documentos solicitados e o P3 não apresentou notificação de pendência documental, porém este último não obteve nenhuma movimentação por um período superior a 365 dias. Pessoa et al., (2016) define como um dos entraves no processo de licenciamento a inconformidade documental com os termos de referência, sendo necessário a emissão de notificação de pendências.

$\mathrm{O}$ índice variou entre a classificação de baixa conformidade equivalente a 33 (trinta e três) para P3, e média conformidade de 43 (quarenta e três) para P1, 49 para P2 e 51 (cinquenta e um) para P4. Cabe salientar que os baixos índices alcançados pelas variáveis relacionadas ao procedimento técnico exercido pelo órgão foram influenciados majoritariamente pelo tempo decorrido de tramitação no órgão, critério diretamente relacionado ao regime burocrático do órgão gestor. Paludo (2010) descreve como uma disfunção marcante do modelo de administração burocrática a lentidão no processo de tomada de decisão.

A lentidão do funcionamento público frente às liberações evidencia falta de comunicação entre o agente regulador e o particular, de modo que não foi possível determinar somente um indivíduo responsável pelas falhas do processo. No que tange o empreendedor, a omissão de dados ou ainda apresentação de dados não relacionados ao processo foram fatores determinantes para o prolongamento na tramitação dos processos entre os setores. A exemplo, podemos citar que uma das empresas apresentou documento de autorização de explotação para ouro, no entanto buscava-se liberação de licença para minério de manganês, o que pode ter influenciado no andamento do processo frente ao órgão

Em uma análise geral dos quatro casos estudados tem-se como resultante que dentre todos os empreendimentos a instituição P4 foi a que obteve a pior pontuação, sendo seus índices insuficientes para o andamento do processo. Isso se deu devido ao maior peso atribuído ao item 4 (quatro) do Índice de Concordância Legal, que analisa o estudo fornecido aos empreendimentos pela empresa solicitante. Em contraste, a empresa P2 obteve a melhor pontuação segundo os índices de Concordância Legal e Técnica.

Desse modo, a regulamentação proposta (Brasil, 2004) pode levar a redução do número de processos protocolados e consequentemente o aumento da eficiência, associada à produtividade e desempenho do procedimento administrativo (MATIAS-PEREIRA, 2018). Todavia, não existem garantias da manutenção da efetividade finalística do instrumento de controle de um procedimento regulador mais flexível. Neste sentido, Santos et al. (2019) enfatiza como a fragilização dos instrumentos normativos de gestão ambiental nacional podem estimular o descaso com o conhecimento científico e jurídico.

\section{Conclusão}

O licenciamento ambiental de atividades minerárias é o principal instrumento de controle dos órgãos ambientais e, por isso, a legislação referente a este tópico não pode apresentar brechas para a ocorrência de falhas. Sendo assim, este estudo indicou que do ponto de vista processual a efetividade do licenciamento dentro do órgão não é tão efetiva quanto deveria, uma vez que algumas lacunas foram identificadas durante a análise dos documentos presentes no site da Secretaria de Meio Ambiente.

Dessa forma, podemos apontar a comunicação como uma lacuna do sistema, ao passo que entendemos que esse seja um princípio básico para o funcionamento satisfatório tanto dos setores públicos e privados. Além disso, acredita-se que não há como iniciar um estudo ambiental sem a comunicação clara do que se deve apresentar, ou ainda de como será avaliado o mesmo. 
Todas as disfunções encontradas no procedimento de licenciamento no estado do Pará caracterizam um rito processual burocrático por parte da administração pública, todavia, as imprecisões cometidas pelos empresários ou seus representantes estão diretamente relacionadas à dinâmica do processo. Em suma, a morosidade causada pela exigência de documentações complementares não se sucederia se estes apresentassem o aprofundamento exigido para uma atividade de significativo impacto como a exploração mineral.

Recomenda-se que sejam apresentadas, primeiramente por parte do órgão regulador, o estabelecimento de uma metodologia atual e especifica de análise dos componentes ambientais, visto que a grande variedade de metodologias adotadas para a avaliação do meio ambiente pode dificultar a efetividade processual dentro do órgão, uma vez que qualquer metodologia está sujeita ao subjetivismo.

A criação de um guia formal para o empreendedor a respeito da tramitação processual dentro do órgão, nos quais devem ser explicadas todas as etapas e informações necessárias para minimizar o tempo de andamento do processo, faz-se necessária afim de que os particulares compreendam o rito processual adotado pela administração pública. Ainda dentro do guia, recomenda-se que sejam esclarecidos os critérios adotados para análise de documentos legais e técnicos.

Para o sistema SIMLAM cabem recomendações de melhoria na acessibilidade e melhor organização das informações prestadas ao contribuinte, apresentando, por exemplo, para cada empreendimento fluxogramas para visualização do status do processo, tornando mais fácil o acompanhamento. Os entraves encontrados no procedimento de licenciamento ambiental hoje vigente reforçam a necessidade de contínua discussão e melhoria dos dispositivos administrativos voltados ao controle e manutenção da qualidade do meio ambiente.

Dessa maneira espera-se que este estudo possa auxiliar artigos futuros que venham apontar as demais causas para o baixo desempenho técnico dentro dos órgãos públicos e que acabam comprometendo o objetivo principal do licenciamento ambiental. Do mesmo modo espera-se que com todas as lacunas apresentadas pelo meio acadêmico haja atualização da legislação para que não exista brechas para o descumprimento do processo apresentado pelos proponentes.

\section{Referências}

Afonso, J. C. (2019). Manganês no brasil: descoberta, extração, consumo e comercialização numa perspectiva histórica. Química Nova, 42 (10), $1172-1183$.

Agência Nacional de Mineração-ANM. (2020) Anuário Mineral Brasileiro. 434. http://www.anm.gov.br/dnpm/publicacoes/serie-estatisticas-e-economiamineral/anuario-mineral/anuario-mineral-brasileiro/amb_2018.pdf.

Raimundo e Almeida, M. R., \& Montaño, M. (2015). Benchmarking na avaliação de impacto ambiental: o sistema mineiro frente às melhores práticas internacionais. Sociedade \& Natureza, 27(1), 81-96.

Brasil (1981). Lei n. 6.938. http://www.planalto.gov.br/ccivil_03/Leis/L6938.htm.

Brasil (2011). Lei Complementar nº. 140/2011. http://www.planalto.gov.br/ CCIVIL_03/LEIS/LCP/Lcp140.htm.

Brasil (2004). Projeto de Lei no 3.729. https://www.camara.leg.br/proposicoesWeb/fichadetramitacao?idProposicao=257161.

Chaves, L. S. S. (2013). Impactos Ambientais gerados por mineração no município de Capanema-PA. In IV Congresso Brasileiro de Gestão Ambiental.

Conselho Nacional de Meio Ambiente - CONAMA (1986) Resolução nº 1. http://www2.mma.gov.br/port/conama/res/res86/res0186.html.

Conselho Nacional de Meio Ambiente - CONAMA (1990) Resolução n 9. http://www2.mma.gov.br/port/conama/legiabre.cfm?codlegi=106.

Conselho Nacional de Meio Ambiente - CONAMA (1997) Resolução no 237. http://www2.mma.gov.br/port/conama/res/res97/res23797.html

Da Silva, J. M. (2009). Território e mineração na Amazônia paraense norte do Brasil. Anais do EGAL, Montevidéu, Uruguay.

Dias, T. G.; Caxito (2018); Manganês - http://recursomineralmg.codemge.com.br/wp-content/uploads/2018/10/Manganes.pdf.

Farias, T. (2019) Discussão a respeito da possibilidade de agilização do licenciamento ambiental. https://www.conjur.com.br/2019-jan-12/ambientejuridicodiscussao-respeito-agilizacao-licenciamento-ambiental.

Fatorelli, L., \& Mertens, F. (2010). Integração de políticas e governança ambiental: o caso do licenciamento rural no Brasil. Ambiente \& Sociedade, 13(2), 401-415. 
Research, Society and Development, v. 10, n. 6, e23910615476, 2021

(CC BY 4.0) | ISSN 2525-3409 | DOI: http://dx.doi.org/10.33448/rsd-v10i6.15476

Fonseca, A., \& Resende, L. (2016). Boas práticas de transparência, informatização e comunicação social no licenciamento ambiental brasileiro: uma análise comparada dos websites dos órgãos licenciadores estaduais. Engenharia Sanitaria e Ambiental, 21(2), 295-306.

Fonseca, A., Montaño, M., \& Moretto, E. M. (2017). A importância do conhecimento científico para o aprimoramento do Licenciamento e da Avaliação de Impacto Ambiental no Brasil. Desenvolvimento e Meio Ambiente, 43.

Gallardo, A. L. C. F., da Silva, J. C., Gaudereto, G. L., \& Sozinho, D. W. F. (2017). A avaliação de impactos cumulativos no planejamento ambiental de hidrelétricas na bacia do rio Teles Pires (região amazônica). Desenvolvimento e Meio ambiente, 43.

Gay, Raul Carvalho. O silêncio administrativo e sua aplicação no licenciamento ambiental. 2019.

Gil, A. C. (2002). Como elaborar projetos de pesquisa (4, 175). Atlas.

Macambira, J. B. (2003). O ambiente deposicional da Formação Carajás e uma proposta de modelo evolutivo para a Bacia Grão Pará.

Matias-Pereira, J. (2018). Administração pública.

Medeiros, A. B. (2018). Retrocesso ambiental: o desmonte do licenciamento ambiental com o substitutivo ao projeto de lei $\mathrm{n}^{\mathrm{o}} 3.729 / 2004$ que cria a lei geral do licenciamento ambiental.

Milaré, É. (2015). Direito do ambiente. Thomson Reuters Revista dos Tribunais.

Miranda, A. C. P., da Silva, A. C., Júnior, C. J. F., da Silva, C. G., \& de Sousa, E. D. S. (2016). Modificações no processo de licenciamento ambiental: Avanços ou retrocessos? In VII Congresso Brasileiro de Gestão Ambiental (pp. 1-5).

Monteiro, M. D. A. (2005). Meio século de mineração industrial na Amazônia e suas implicações para o desenvolvimento regional. Estudos avançados, 19(53), $187-207$.

Oliveira, F. S. D., Prado Filho, J. F. D., Rocha, C. P. F., \& Fonseca, A. D. F. C. (2016). Licenciamento ambiental simplificado na região sudeste brasileira: conceitos, procedimentos e implicações.

de Oliveira, P. M., \& Andery, P. R. P. (2017). O processo de licenciamento ambiental no projeto de empreendimentos industriais de mineração. Gestão \& Tecnologia de Projetos, 12(2), 135-150.

Paludo, A. V. (2010). Administração pública. Elsevier.

Pará (2019). Instrução Normativa no 11. https://www.semas.pa.gov.br/legislacao/publico/view/1510.

de Melo Pessoa, A. A., da Paz Justino, A. N., de Farias, F. H. C., da Silva, J. M. D., \& de Sousa, V. R. M. (2016). Análise da eficiência, eficácia e efetividade na administração pública: o caso do IDEMA/RN. Revista ESPACIOS| Vol. 37 (Nº8) Año 2016.

Polícia Federal (2020). Polícia Federal apreende 200 toneladas de minério de manganês que seriam exportadas ilegalmente. http://www.pf.gov.br/imprensa/noticias/2020/03-noticias-de-marco-de-2020/policia-federal-apreende-200-toneladas-de-minerio-de-manganes-que-seriamexportadas-ilegalmente.

Sanchez, L. E. (1993). Os papéis da avaliação de impacto ambiental. Avaliação de impacto ambiental: situação atual e perspectivas. Edusp, $15-33$.

Santos, J. D. L. (2019). O controvertido projeto de lei que regulamenta o licenciamento ambiental: o dilema entre o progresso econômico e o retrocesso ambiental.

Silva Júnior, L. (2016). Avaliação da efetividade dos processos de licenciamento ambiental de empreendimentos de mineração do Sul de Minas Gerais. 2016. 121 (Doctoral dissertation, Dissertação (Mestrado em Meio Ambiente e Recursos Hídricos). Instituto de Recursos Naturais-Universidade Federal de Itajubá, Itajubá-MG).

Silva Júnior, L. D., Alvarenga, M. I. N., \& Garcia, S. R. (2018). Avaliação da qualidade dos processos de licenciamento ambiental de empreendimentos de mineração em Minas Gerais. Ambiente \& Sociedade, 21. 